\title{
Training habits and lower limb injury prevention in parkour practitioners
}

\author{
Sidney Grosprêtre ${ }^{1,2,{ }^{*}}$ (D) and Sami El Khattabi ${ }^{2}$ \\ ${ }^{1}$ EA4660, C3S Culture Sport Health Society, University of Bourgogne-Franche-Comté, Besançon, France \\ 2 PRESS (Pôle de Ressources et d'Expertise Sportive et Scientifique), French Parkour Federation (FPK), Strasbourg, France
}

Received 27 July 2021, Accepted 27 November 2021

\begin{abstract}
Parkour consists of overcoming obstacles mostly in an urban landscape. Little is known regarding usual training habits and injury risks of traceurs, i.e., parkour practitioners. In this study, a 20-min survey have been fulfilled by a population of traceurs regarding training load, habits (type of warm up, physical conditioning, stretching), type of footwear, and number and type of ankle- and knee-injuries during their career. A total of 180 responses were analyzed ( $24.4 \pm 5.9$ years old, $21.7 \%$ female, $6.0 \pm 3.9$ years of experience). Participants reported to train 1 to 7 times per week for a mean duration of $2.2 \mathrm{~h}$. $76 \%$ practiced stretching exercises. $75.6 \%$ practiced physical conditioning in addition to their parkour training (weightlifting, functional exercises). Injury rate was 1.7 per $1000 \mathrm{~h}$ of training, mostly ankle sprains and knee contusions. Number of injury and training load were positively correlated. The lack of physical conditioning was also a factor of injury. Knee injuries have been more frequent on participants wearing minimalist shoes. Although training appears well auto-organized and the injury rate quite low some pitfalls require attention, notably in training planning, warm-up, stretching and conditioning. Building training and coaching methods specific to parkour appears essential.
\end{abstract}

Key words: freeruning, knee, ankle, sprain

Résumé - Méthodes d'entraînement et prévention des blessures des membres inférieurs chez les pratiquants de parkour. Le parkour consiste à franchir des obstacles le plus souvent en milieu urbain. On sait peu de choses sur les habitudes d'entraînement et les risques de blessures des traceurs, c'est-à-dire des pratiquants de parkour. Dans cette étude, un sondage de 20 minutes a été rempli par une population de traceurs concernant la charge d'entraînement, les habitudes (type d'échauffement, conditionnement physique, étirements), le type de chaussures, et le nombre et le type de blessures à la cheville et au genou durant leur carrière de sportif. Au total, 180 réponses ont été analysées $(24,4 \pm 5,9$ ans, 21,7\% de femmes, 6,0 $\pm 3,9$ ans d'expérience). Les participants ont déclaré s'entraîner de 1 à 7 fois par semaine pendant une durée moyenne de 2,2 h. $76 \%$ pratiquaient des exercices d'étirement. $75,6 \%$ pratiquaient un conditionnement physique en plus de leur entraînement au parkour (haltérophilie, exercices fonctionnels). Le taux de blessures était de 1,7 pour 1000 h d'entraînement, principalement des entorses de la cheville et des contusions du genou. Le nombre de blessures et la charge d'entraînement étaient positivement corrélés. Le manque de conditionnement physique était également un facteur de blessure. Les blessures au genou ont été plus fréquentes chez les participants portant des chaussures minimalistes. Bien que l'entraînement semble bien auto-organisé et le taux de blessures assez faible, certains points nécessitent une attention particulière, notamment dans la planification de l'entraînement, l'échauffement, les étirements et le conditionnement physique. Construire des méthodes d'entraînement et de coaching spécifiques au parkour semble essentiel.

Mots clés : freeruning, genou, cheville, entorse 


\section{Introduction}

Parkour is a modern physical activity that consists of overcoming obstacle mostly in an urban landscape. Its popularity has grown over the past two decades, mainly by the impressive audience generated by online video platforms. Sports organizations have also emerged to develop the activity and now in many countries it has become an official sport. Its interest has also spread to an international level, to such an extent that the International Olympic Committee is now studying the possibility of its integration to the Olympic Games (Minogue, 2018). Although the number of parkour practitioners is constantly increasing throughout the world, scientific knowledge is still missing regarding this activity.

Parkour practitioners, commonly called "traceurs", use different skills, such as running, jumping, climbing, rolling, as well as movements specific to the discipline (Grosprêtre \& Lepers, 2016; Puddle \& Maulder, 2013; Strafford, van der Steen, Davids, \& Stone, 2018). Casually, as in any sport, to practice in an optimal and safe way it is necessary to adopt a rigorous, regular, and adapted physical preparation. This preparation would highly help to reduce injuries (Da Rocha et al., 2014). However, the spectacular nature of performances displayed in online videos and overall massive media which, on one hand, contributes to the popularity of the discipline has also led, on the other hand, to a consideration of parkour as a traumatic and dangerous activity from a popular opinion (Cazenave \& Michel, 2008).

Yet, despite some sparse data in the literature, little is known regarding injury incidence and risk factors in parkour. Many factors may predispose traceurs to the occurrence of injuries. Some are general and common to all sports, while others are specific to parkour. The present article will try to bring additional clues on that matter by analyzing the training habits of traceurs and their injury incidence. Particularly, since parkour involves lots of massive drops jumps and requires an important power of the legs (Grosprêtre \& Lepers, 2016) the present study focused on lower limb, i.e., knee and ankle injuries. The targeted choice of knee and ankle injuries can be explained by the fact that these are the most frequent locations encountered in the practice of parkour (Da Rocha et al., 2014; Rossheim \& Stephenson, 2017).

The aim of the present article is twofold: i) to identify risk factors of injury that could be predominant in parkour, and ii) to assess injury incidence through a survey filled by a representative panel of traceurs. Finally, based on these materials, we proposed practical recommendation to prevent such injuries.

\section{Methods}

A survey was established to collect information from a panel of representative French practitioners. There were three main inclusion criteria to fulfill the survey: 1) to be currently practicing parkour, 2) to be French-speaking and 3 ) to be at least 15 years old. This last choice was partly made due to possible misunderstanding of complex terms, but above all to focus on late teenagers, young adults and adults because they represent the main range of age in parkour (Grosprêtre \& Lepers, 2016) and because children present very different physiological factors. There was, on the contrary, no maximal age to answer the survey.

The questionnaire was distributed by the French parkour federation to its network, in order to collect data from a representative panel of parkour practitioners, with regards to age, gender and experience(Grosprêtre \& Lepers, 2016). Number of questions varied from one participant to another depending on their previous injury experiences, since they were able to skip question if not concerned. The mean duration to fulfill the survey was estimated at $20 \mathrm{~min}$. Different types of questions were displayed, binary (yes or no), multiple-choice questions or open-ended. The questions included general information (age, professional category, etc), sports practices, parkour training habits and questions relative to several preidentified risk of injuries (see below). Questions were then asked more specifically on previous knee and ankle injuries (number and type of injuries, medical care or not, etc.).

\subsection{Evaluation of intrinsic factors}

Besides inherent physiological factors, the training organization and personal habits also represent an important risk of injury. Especially the presence and importance of warm-up is often reported as an important factor of injury risk particularly in the lower limb (Pieters, Wezenbeek, De Ridder, Witvrouw, \& Willems, 2020). Since traceurs must manage important physical constraints, it can also easily be argued that without a proper physical preparation the traceur is exposed to a significantly higher risk of injury. Regarding a possible dose-effect response, overtraining is often also presented as one of the main risk factor of injury (Egermann, Brocai, Lill, \& Schmitt, 2003; Vleck \& Garbutt, 1998). For instance, the average number of hours of training per day could be a risk factor for parkour injuries (Da Rocha et al., 2014).

A limited range of motion in lower limb joint could not also provide sufficient room to dissipate the energy and absorb the impact of a high drop landing. Previous studies showed that using a greater range of motion in flexion at the hip, knee and ankle will allow the reaction force from the ground to be dispersed through the musculoskeletal system over a longer period of time, thus reducing the risk of injury (Bressel \& Cronin, 2005; Cortes et al., 2007; Gross \& Nelson, 1988). Studies carried out on runners (Jamtvedt et al., 2010; Kay \& Blazevich, 2012) suggest that regular muscular stretching, at a distance from training, would have a positive influence on the incidence of injury. On the contrary, stretching muscles prior to the exercise would not decrease the incidence of injury and may even increase it.

Regarding other training habits and life hygiene in general, a lack of hydration also was suggested as an important risk factor of injuries in sport. Dehydration was 
shown to impair thermoregulation and water balance, which may cause inhibition of cognitive function and motor performance (Hillyer, Menon, \& Singh, 2015). In Parkour, skills are as important as power to prevent falling and injuries. Therefore, dehydration appears to be a significant risk factor for injury in such activity.

Apart from training organization, mastering technical skills are also important to limit the risk of falling and therefore causing injury. Therefore, in parkour the ability to perform a safe landing is important to minimize the risk of injury and to increase the longevity of the traceurs (Maldonado, Soueres, \& Watier, 2018; Standing \& Maulder, 2015). It was shown that in the practice of team sports requiring jumps, poor landing technique is the primary cause of knee and ankle injuries (Hume \& Steele, 2000). Consequently, several questions focused on traceur's landing technique. Specifically, another important factor of a safer landing in parkour, which is highly specific to the discipline, is the execution of the roll. The roll is usually performed following a jump with a certain forward horizontal speed. The roll will often be used after high drop jumps, especially those that are larger than the size of the tracer making the jump (Puddle \& Maulder, 2013).

To further the exploration of parkour techniques, contrary to traditional drop jump landing some parkour movements are asymmetrical. For instance, long jumps with prior run-up are performed by a unipedal impulse. Landing on one foot after a long jump has also become more and more common as it allows to start running again in a more efficient way. During such jumps it is easy to imagine that the muscular and articular constraints of the supporting foot and the landing foot are not the same. Such asymmetries between legs is often proposed as an important risk of injury (Brown, O'Donovan, Hasselquist, Corner, \& Schiffman, 2016; Zhang, Bates, \& Dufek, 2020). We could thus think that this asymmetry of movement and this preferential side could be the cause of unbalanced constraints over lower limbs which could represent a risk of injury in traceurs.

\subsection{Evaluation of extrinsic factors}

Participants were also asked to answer several question relative to some specific extrinsic factors, relative to their training environment and material. Regarding proper equipment, it is certainly much reduced as compared to other sport activities. Nonetheless, regarding lower limb injury prevention, the type of footwear should be particularly considered. Other types of proper equipment were considered as negligible.

The use of parkour facilities has also been questioned. Although it is initially an outdoor practice, nowadays the development of parkour indoor facilities leads to another form of practice. To our knowledge, no retrospective study was able to assess the impact of indoor versus outdoor practice. It would be easily conceivable that practicing indoor, an optimally controlled environment, would be less likely to cause injury than practicing outdoor. However, the presence of such security can also pay against traceurs safety, increasing risk-taking behavior.

Parkour being practiced in a public environment, in most case with one or several partners, risk of injuries could also easily results from negative effect of an external audience. It appears that the behavior adopted by the practitioner during the practice of parkour as well as his personality can be considered as risk factors for injury. Particularly, young practitioners appear to be prone to a particular sensation-seeking behavior and narcissic personality (Cazenave \& Michel, 2008). Other social aspect, such as the presence or not of parkour supervision as well as its quality, was also questioned.

\subsection{Injuries}

Participants were asked to answer several questions regarding their previous injury experience, at both knee and ankle level. An injury was defined here as a musculoskeletal pain or disorder that stopped the athlete's training for at least several days. Chronic pain and short duration discomfort after a wrong move during training were not considered as injuries here. Participants were asked to report information such as the number and types of injuries, at which time of the year or of the training session they injured. The injuries' incidence rate (hereafter called "injury rate") was calculated as the number of reported injuries per $1000 \mathrm{~h}$ of training, i.e., the ratio of the total number of injuries over the total training volume multiplied by 1000 (ex: 4 injuries in $2000 \mathrm{~h}$ of training results in a rate of 2). Finally, they were also asked to report their feeling about the reason why they injured (fatigue, lack of attention, etc.).

\subsection{Statistical analysis}

Continuous data, e.g., age, training parameters (hours per week, experience, etc), were compared with knee and ankle number of injuries through a Pearson's correlation analysis. Discrete variables with two options (e.g., warm up: yes or no, male or female, stretching or not) were compared to knee and ankle numbers of injuries through Student unpaired two-tailed $t$ test. When the number of options exceeded 2 (e.g., the type of shoes), analysis of variance (ANOVA) was performed.

Since establishing causality between risk factors and an a posteriori analysis of injury occurrences can lead to hazardous yet over interpretation of their potential relationships, we want to raise the fact that the statistical analysis was performed here as an indication and was not deepened and discussed in further details. Such sportinjury statistics data with surveys are to take with caution, being highly dependent upon the multifactorial nature of an injury. A causality cannot be directly established because a significant correlation is found and, on the opposite, an absence of significant statistical 
result does not prove a lack of relationship (statistical power, etc). The limitation of such approach have been summarized in a recent article by Nielsen et al. (2018).

\section{Results}

\subsection{Population characteristics}

Over 200 responses received, the total amount of selected responses was 180 after careful screening of the duplicates, false profiles, and errors (incomplete responses, etc). Age (24.4 \pm 5.9 years old on average) ranged from 15 (the minimum age required to participate in the study) to 49 years old. Over the 180 individuals, 141 were men $(78.3 \%)$ and 39 women $(21.7 \%)$. Regarding jobs, 79 were students (43.9\%), 34 office-workers (18.9\%) and $27(15 \%)$ declared a physically demanding job (sport coaches mainly). Regarding parkour, experiences varied between 3 months and 20 years of practice, with an average of $6.0 \pm 3.9$ years.

\subsection{Training load}

Parkour training frequency varied from daily practice to once a week (average 2.42 times a week). Training duration ranged from $45 \mathrm{~min}$ to $5 \mathrm{~h}$ (average $2 \mathrm{~h}$ and $24 \mathrm{~min})$.

The number of rest days between each training sessions varies from none (8.3\%) to one $(27.2 \%)$, two (35\%) or three $(29.4 \%)$. A certain proportion of participants $(41.7 \%)$ reported beginning a training session by feeling aches and pain from the previous session. 8.9\% of the participants confessed feeling that their amount of training was too much for their own capacities. Over the 180 individuals, 77 $(42.8 \%)$ reported practicing only parkour, and 103 $(57.2 \%)$ reported practicing other activities in parallel to parkour. For these latter, the most common parallel activities were climbing (35.9\%), combat sports (11.7\%), gymnastics $(9.7 \%)$, track and field $(8.7 \%)$ and bodybuilding $(8.7 \%)$.

\subsection{Warm-up}

Over 180 individuals, 156 (86.7\%) declared to perform a warm-up at each training session, meaning that 24 individuals (13.3\%) do not warm up (Fig. 1). Warm-up duration varies between $5 \mathrm{~min}$ and $90 \mathrm{~min}$. The mean warm-up time was $16.8 \mathrm{~min}$. Warm-up program included joint mobilization (95.5\%), small parkour moves (90.4\%), muscular exercises $(83.3 \%)$ and cardio-vascular exercises (64.1\%).

\subsection{Physical fitness}

Out of the total sample, 136 individuals $(75.6 \%)$ reported practicing specific physical conditioning in addition to their parkour training, while $44(24.4 \%)$ did not (Fig. 1). The timing of conditioning varied, being performed either during (12.5\%), outside $(24.3 \%)$ or both during and outside (63.2\%) their parkour sessions.
The proportion of time dedicated to physical conditioning in total amount of training time varied (Fig. 1). The content of this conditioning was diverse from body weight exercises $(93.4 \%)$, repeating simple parkour movements $(72.1 \%)$, practicing free $(33.8 \%)$ or guided (18.4\%) weight lifting. Some of the participants also reported practicing other sport activities as physical conditioning, such as climbing $(25.5 \%)$ or track and field $(12.5 \%)$. Among the main reasons given by participants for performing physical conditioning, it could be noted an interest in improving parkour performances (89.7\%), lowering risk of injury (78.7\%), gaining endurance to increase training duration (56.6\%) or for aesthetic purpose $(27.2 \%)$.

\subsection{Stretching}

Out of 180 individuals, 137 (76.1\%) declared practicing stretching for the lower limbs (Fig. 1). The timing of stretching varied from one participant to another (Fig. 1). The frequency of stretching also varies, some reported stretching systematically during each training session $(38.7 \%)$, other once $(17.5 \%)$ or several times a week $(38 \%)$.

\subsection{Hydration}

Participants reported drinking from 0.5 to $4.5 \mathrm{~L}$ of water daily (mean: $1.45 \mathrm{~L}$ ). 77 reported drinking before training (42.8\%), 140 during (77.8\%), and 139 after $(77.2 \%)$.

\subsection{Technical aspects}

Regarding landing, 172 individuals $(95.6 \%)$ declared that their heels do not hit the ground in most of their jumps performed. 98 individuals (54.4\%) stated performing a roll when jump height reach their own height or more.

\subsection{Lower limb asymmetry}

Over the whole panel, 137 individuals (76.1\%) declared to always use the same foot for asymmetrical jumps (i.e., long jumps). To the question: "do you feel a difficulty performing jumps on both sides?", 117 individuals (65\%) answered YES.

\subsection{Materials}

Regarding the training shoes, more than half of the participants $(53 \%)$ reported wearing running sneakers with a drop from heel to forefoot, while other reported wearing light flat shoes (35\%) or minimalist shoes (12\%).

\subsection{Environment}

Only four individuals $(2.2 \%)$ reported practicing only indoor in parkour facilities. On the contrary, 58 individuals $(32.2 \%)$ reported practicing parkour only outdoor. The remaining $118(65.6 \%)$ practiced both indoors and outdoors. When asking these individuals if they felt less 


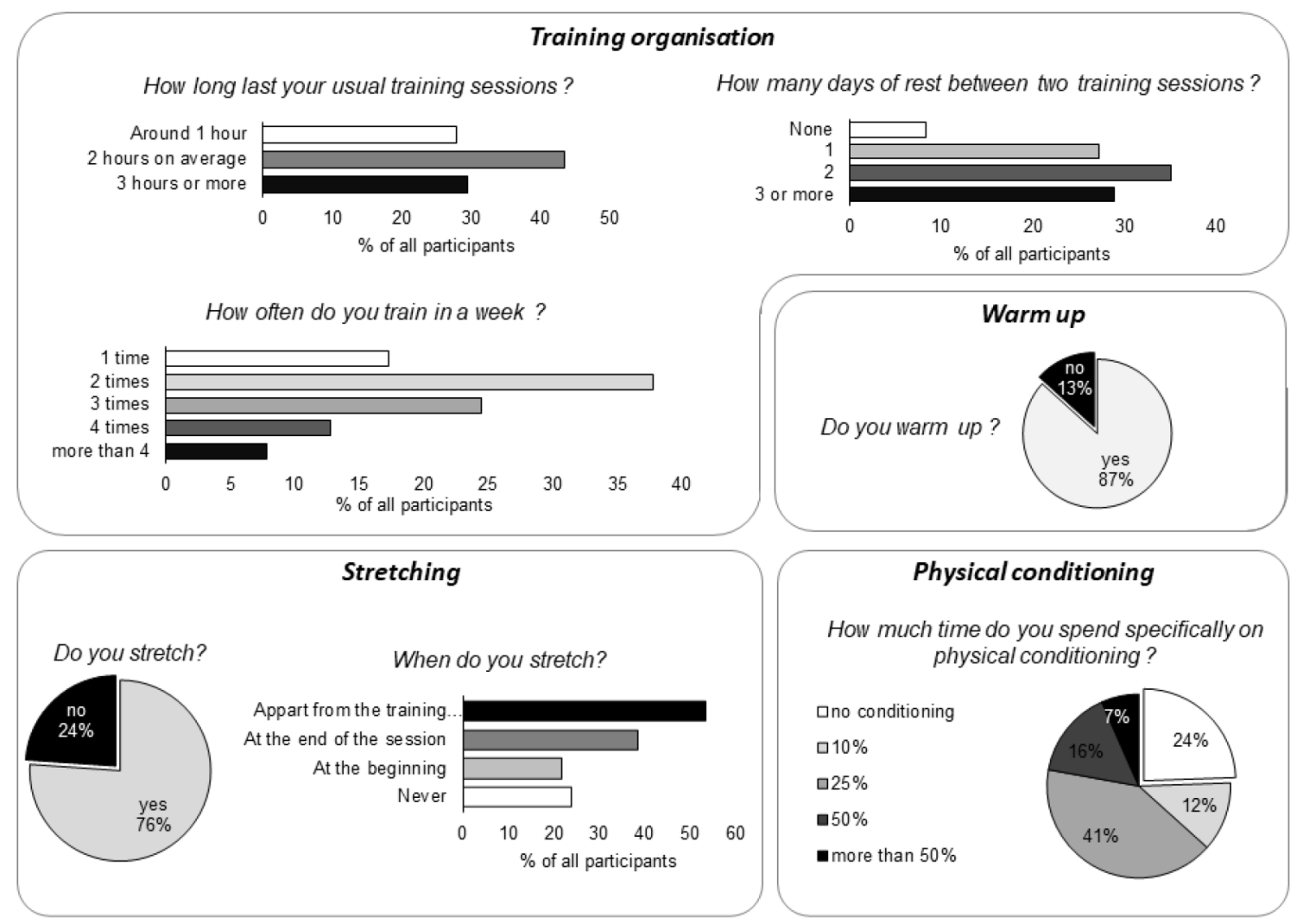

Fig. 1. Summary of the training habits of traceurs. Responses to the survey are expressed as percentage of total responses $(\mathrm{n}=180)$.

confident when going outside after practicing indoor, 45 individuals $(38.1 \%)$ answered YES, the remaining 73 $(61.9 \%)$ answered NO.

On the 122 individuals that used indoor parkour facilities, $107(87.7 \%)$ reported using gymnastics mats, and 15 individuals (12.3\%) reported practicing without such protective equipment, even indoor.

\subsection{Coaching}

A certain proportion of participants reported having started parkour on their own without supervision, either alone $(16.7 \%)$ or with other beginners friends (23.9\%). 36 traceurs $(20 \%)$ reported beginning under the supervision of experienced traceurs, and 64 others $(35.6 \%)$ under the supervision of a professional coach.

\subsection{Sensation-seeking}

Little participants of the panel $(7.2 \%)$ admitted they got injured because someone else convinced them to perform a jump they were not ready for. Some of the participants $(26.1 \%)$ also felt they got injured because they put too much pressure on their own and felt stressed, while $17.8 \%$ of participants reported having faced injuries due to overestimation of their physical abilities.

\subsection{Injuries}

The average number of lower limb injuries for the panel is $1.7 \pm 3.4$ injuries per $1000 \mathrm{~h}$ of training. The most identified causes of injury by the participants themselves were overtraining and lack of vigilance. Indeed, $60 \%$ felt they already injured because they were physically tired, and $53.3 \%$ also because of a poor environment analysis and lack of attention.

Over the 180 individuals, $78(43.3 \%)$ have already injured their knees during their parkour practice. The injury rate for the knee is on average of $1.1 \pm 3.3$ per $1000 \mathrm{~h}$ of training. The most frequent types of knee injury were contusions and sprains (Fig. 2). Recurrences are present for 17 individuals (21.8\% of the injured participants), mostly tendinopathies (2 to 10 recurrences) and contusions. Over the 78 individuals already injured at knee level, 51 saw a medical specialist ( $65.3 \%)$. Finally, $65.4 \%$ of the injured individuals reported continuing to practice despite the pain.

Over the 180 individuals, $67.2 \%$ had already injured their ankle during their parkour practice. Injury rate for the ankle, of $2.3 \pm 3.4$ per $1000 \mathrm{~h}$ of training, was significantly higher than those of the knee $(p<0.001)$. The vast majority of ankle injuries were ligament pathologies such as sprains (Fig. 2) but participants also reported tendon injuries and contusions. Interestingly, $9 \%$ 
A

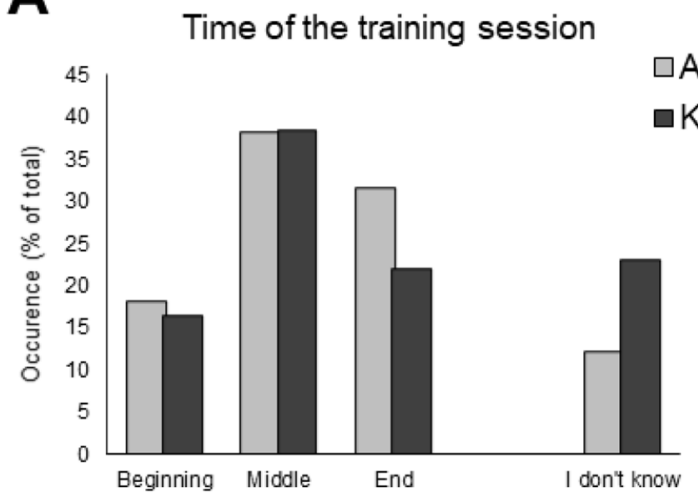

C

Ankle

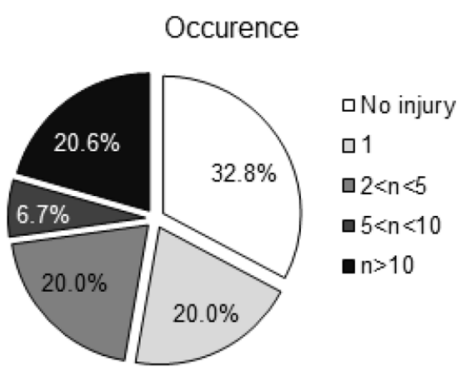

Type of injury

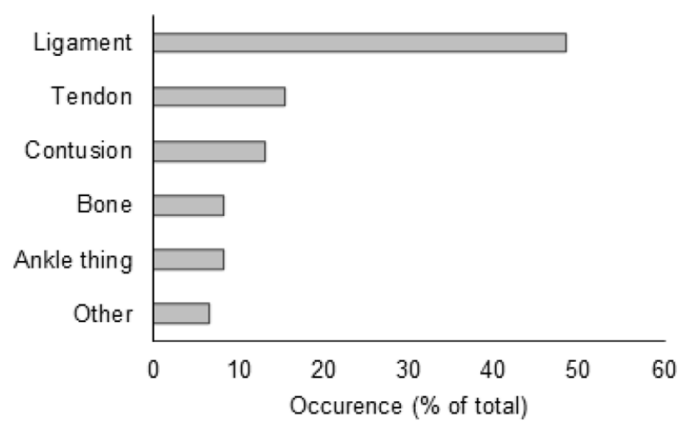

B

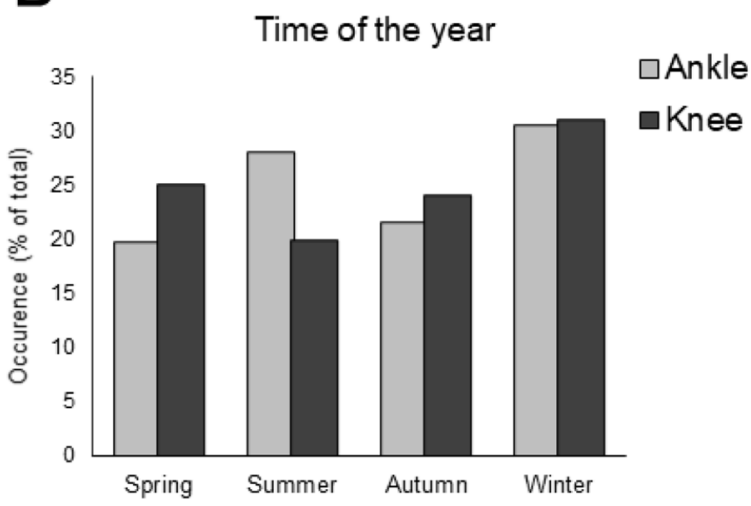

D

Knee

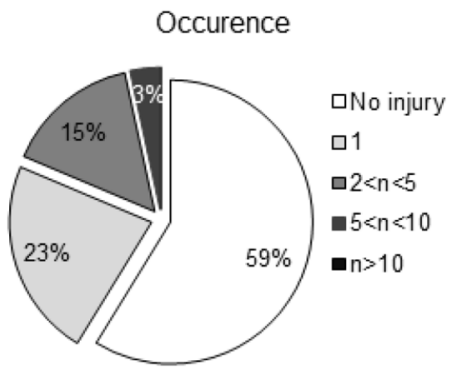

Type of injury

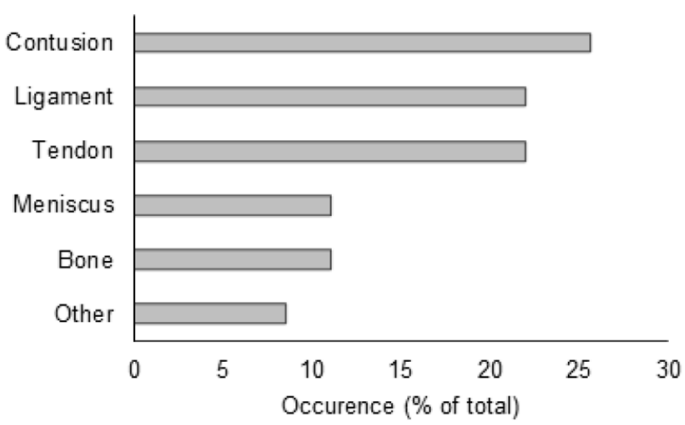

Fig. 2. Summary of injury occurrences in traceurs. A. Occurrences according to the time of the training session they injured, for knee (dark grey) and ankle (light grey) injuries, respectively. B. Occurrences according to the season, for knee (dark grey) and ankle (light grey) injuries, respectively. C. Number and types of ankle injuries. D. Number and types of knee injuries.

of the injured participants reported suffering severe ankle injury named "coin-coin" in French, or "ankle thing" in English. This injury, very specific to parkour, is characterized by a dorsal hyperflexion of the ankle during a forefoot landing on the edge of a wall. Its mechanisms are still not perfectly known, as this dorsal hyperflexion can lead to an extreme stretch of the posterior capsuloligamentary structures or to a crushing of the anterior articular and/or tendinous structures. The number of recurrences was also significantly superior in ankles than in knees $(\mathrm{P}<0.001)$, with $47.1 \%$ of injured participants reporting recurrence of their ankle injuries. Participants were more prone to see a medical specialist for the ankle, since $80.9 \%$ of the participants had their ankle examined. Finally, $47.9 \%$ of the participants reported continuing practicing parkour despite the pain.

\subsection{Statistics}

Among all the tested variables, discrete and continuous, some exhibited significant relationships with the number of injuries per individual, at the knee and/or ankle levels (Fig. 3). A significant negative correlation was found between the number of injuries per individual and the 


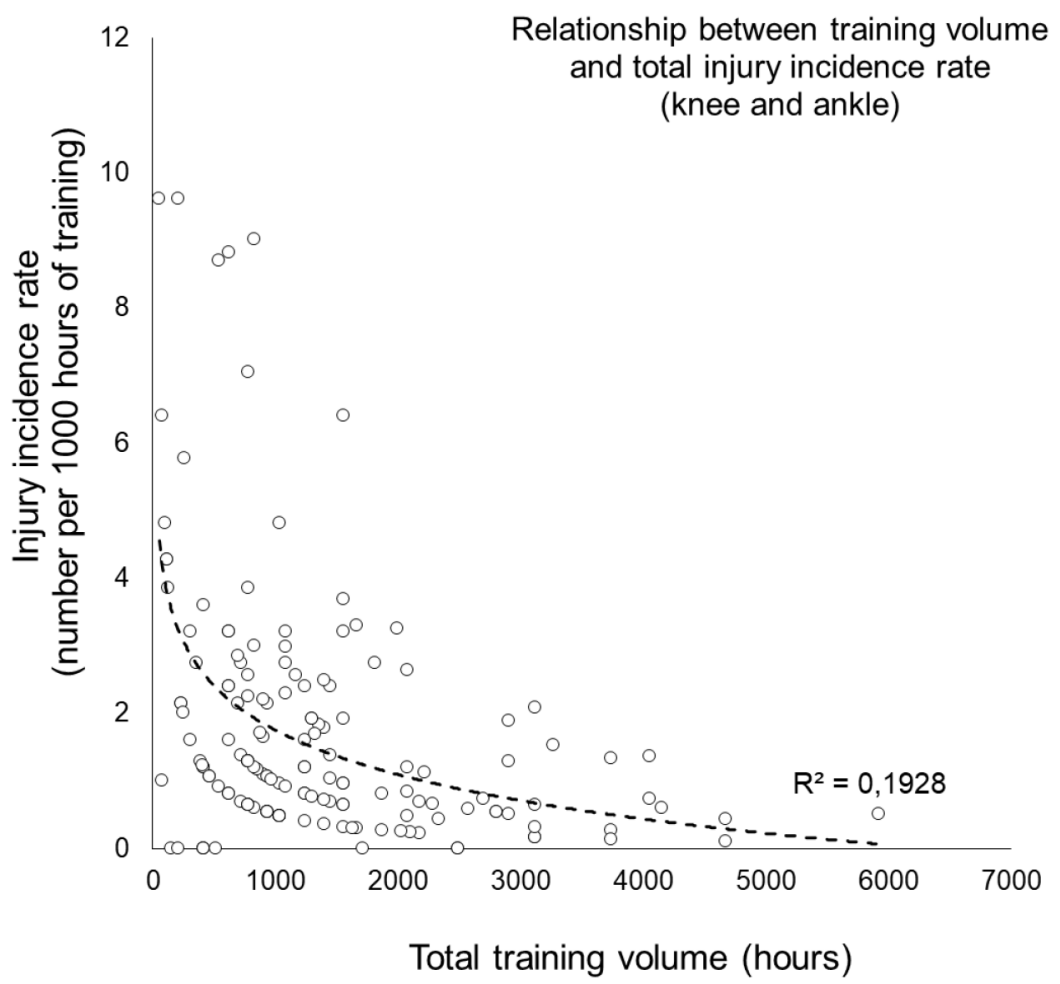

Fig. 3. Relationship between training volume and total injury incidence rate (knee and ankle).

number of weekly training hours $(\mathrm{r}=-0.25, \mathrm{P}<0.01)$. Participants who reported not to warm-up exhibited more knee injuries than those who reported to do so $(\mathrm{P}=0.018)$. As well, significantly higher number of injuries, in ankle and knee, was found in participants who reported not to practice physical conditioning at all as compared to all types and duration of conditioning (all $\mathrm{P}<0.04$ ). Significant differences in the number of knee injuries were found with the factor type of footwear (traditional sneakers, light shoes and minimalist). Participants who reported training with minimalist shoes exhibited more knee injuries than those training with running sneakers $(\mathrm{P}=0.032)$ and light shoes $(\mathrm{P}=0.045)$. On the contrary other variables such as stretching, hydration, sex, type of environment (indoor vs. outdoor) did not reveal significant statistical difference nor correlation with the number of injuries per individual.

\section{Discussion}

The present study aimed at investigating parkour injury incidence on lower limb joints, and its associated risks of injury by analyzing traceur's training habits. Although training in parkour appear well organized and the injury rate quite low in general, the presence of some pitfalls should require attention.

In the present study, the injury rate $(1.7 \pm 3.4$ injuries per $1000 \mathrm{~h}$ ) is in fact among the lowest as compared to other athletes, comparable to cross-fit $(2.4 / 1000 \mathrm{~h}$, (Giordano \& Weisenthal, 2014)), long distance running (Van Gent et al., 2007) or triathlon training (0.69-1.39/
$1000 \mathrm{~h}$ (Zwingenberger et al., 2014)). Injury rate in gymnasts can reach 3.1 per $1000 \mathrm{~h}$ but was also reported much higher in team sports such as soccer $(7.8$ per $1000 \mathrm{~h})$ or basketball (9.1 per $1000 \mathrm{~h}$ ) (Parkkari et al., 2004). Authors are unanimous regarding the fact that injury rate is very much higher during competitions (Summitt, Cotton, Kays, \& Slaven, 2016). Therefore, the quasiabsence of competition in parkour, at least for now, can be accountable for such a low rate. Then, some authors found a significant correlation between weekly hours of training and injuries incidence in triathletes (Egermann et al., 2003; Vleck \& Garbutt, 1998), while other did not (Collins, Wagner, Peterson, \& Storey, 1989; O'toole, Hiller, Smith, \& Sisk, 1989). In the present panel of traceurs, a relationship was found between weekly hours of training and injuries occurrences, as previously reported (Da Rocha et al., 2014). The main frequent injuries reported by the panel were sprains for the ankle, at a large majority, and contusions for the knee. Lower limb injuries were also reported as predominant in a study of Rossheim et al. investigating the hospital admission due to parkour in the U.S.A (Rossheim \& Stephenson, 2017), in which they also showed that bad landings were the major cause of injuries.

First of all, as reported regarding sport-related injuries in general, age can be a risk factor but since parkour has spread only for twenty years, it is not for now a main risk factor. If we take the example of Achilles tendon pathologies, several sources establish the fact that an age above 30 years increases the risk of injury (Longo, Petrillo, Maffulli, \& Denaro, 2013; Mazzone \& Mccue, 
2002), as tendon degeneration begins early. The panel of participants was mostly composed of young practitioners between 15 and 25. Most participants were men, with a $20 \%$ proportion of women. No particular effect of age nor sex was found on injury rate or risk factors. We recommend however for the future years to adapt training strategies according the age of the participants.

It is even more important to focus on training organization. Indeed, a training overload, in terms of frequency, duration and intensity of training sessions, might represent an important risk factor for injury in parkour (Da Rocha et al., 2014). It was for instance recommended not to exceed $3 \mathrm{~h}$ of parkour training in a row (Da Rocha et al., 2014). Our questionnaire revealed that individuals train from $45 \mathrm{~min}$ up to $5 \mathrm{~h}$, with a mean training time of $2 \mathrm{~h}$. Only speaking about training duration, the majority therefore trains in a non-excessive way. The mean frequency was 2.4 training session per week, which means that the majority of tracers have at least 2 to 3 days of rest in-between. However, it should be noticed that $57.2 \%$ practice another sport in parallel to parkour. Interestingly $60 \%$ of the participants felt that they injured because they were physically tired. Therefore, parkour training load should be taken in consideration but more importantly incorporated in a global workload, including other sport practices and daily activities.

To limit the effect of overload and fatigue, dedicating a part of the training time to physical conditioning appear crucial for such impacting activity. Out of the total sample, $75.6 \%$ reported dedicating a significant part of their training to physical conditioning. Furthermore, these latter reported significantly less injuries than those who do not practice physical conditioning. The proportion of this conditioning over the total training duration as well as its composition varied among participants, but this showed that physical preparation is an integral part of the traceurs' training. However, regarding other training habits, the survey revealing some points that could be largely improved, for instance regarding warm-up.

The literature about warm-up strategies and importance is well documented and strongly recommend to take this part of the training session seriously to prepare the musculo-skelettal system for the constraints of training (Hess, 2010; Leppilahti \& Orava, 1998; Park et al., 2011; Safran, Garrett, Seaber, Glisson, \& Ribbeck, 1988). However, although a large majority of traceurs reported to do so, still more than $13 \%$ reported not to warm up at all. Moreover, these latter showed a significantly higher number of injuries. The mean warm-up duration was about 15 min, consisting mostly in joint mobility, physical conditioning and small parkour movements. A large proportion also reported performing cardio-vascular exercises $(64.1 \%)$, or stretching. Although there is no specific parkour-related literature on how to warm-up, a more generic literature can bring some clues. To properly prepare the musculo-skeletal system, and especially lower limb tendons for high plyometric activities, it was shown very recently that warm-up should include sufficient mechanical stress by performing intensive exercise
(Pieters et al., 2020), and that stretching or light joint mobility was inefficient or even deleterious. Regarding stretching habits specifically, around $20 \%$ of participants reported to stretch before parkour training or during the warm-up. Such time for stretching is not recommended for plyometric performance (Behm \& Kibele, 2007; Shrier, 2004), even if its integral part of the warm-up (Winchester, Nelson, Landin, Young, \& Schexnayder, 2008). Similarly, it is not recommended to perform too much stretching exercise after an intensive plyometric and/or eccentric training, as it is the main component of parkour training (Grosprêtre \& Lepers, 2016). Indeed, contrary to a common opinion, to stretch after an intensive exercise does not reduce delayed muscle soreness, and can even increase muscle damage (Lund, Vestergaard-Poulsen, Kanstrup, \& Sejrsen, 1998). Performing stretching exercise can still be recommended in parkour, but performed at different time from the training session. Indeed, in parkour as in many other athletic activities, landing safely requires to use a great range of motion of the lower joints. Indeed, this was shown to allow trained athletes to absorb in a more efficient way the impact and thus reduce the longterm risk of injury (Bressel \& Cronin, 2005; Cortes, Onate, Abrantes, Gagen, Dowling, \& Van Lunen, 2007; Gross \& Nelson, 1988). Even if not performed properly, over the total sample, $76.1 \%$ reported performing stretching exercises on a regular basis.

Another habit that could be improved is water intake. Water supply, including water from food $(20 \%)$ is often linked with an inhibition of cognitive functions and motor performance (Hillyer et al., 2015), therefore representing a factor of injuries, especially of soft tissues, i.e., tendons and ligaments, mainly composed of water. Usual recommendation are between 1.2 and $2.5 \mathrm{~L}$ of water per day (excluding food), and up to $3.2 \mathrm{~L}$ if the individual practices moderate physical activity (Greenleaf et al., 1977). In the present population, the mean daily hydration was $1.25 \mathrm{~L}$, which is in the lower range of daily recommendation.

Beside training habits, a lack of technical skills also represents an important risk of injury. In parkour particularly, landing technique is very specific and should be mastered to limit its impact and reduce the risk of injury (Standing \& Maulder, 2015). For example, heel contact during landing could indicates either a lack of technique or an inability to control the eccentric forces present when reducing speed during the landing phase (Gross \& Nelson, 1988). To that matter, traceurs exhibit greater leg eccentric forces than untrained participants or gymnasts (Grosprêtre \& Lepers, 2016). In parkour, landing on the forefoot and avoiding heel contact was for instance shown to lessen the ground reaction force and the sound produced at landing (Standing \& Maulder, 2015). Other characteristics such as an increased range of motion at landing or an extended duration of landing movement allowed traceurs to dissipate more energy and execute softer landing than untrained (Maldonado et al., 2018). It emerged from the survey that a large majority of practitioners $(95.6 \%)$ uses this forefoot technique. When the drop is high (i.e., more than the traceur's height) 
performing a roll has also been shown to limit the impact at landing (Puddle \& Maulder, 2013). Although this could be improved, a large proportion of participants (54.4\%) also declared performing a roll when the drop was high, i.e., equal or more that their body height.

To still focus on parkour skills, a majority of participants $(76.1 \%)$ reported developing a preferential side during their parkour training, for unilateral techniques. In other disciplines, the asymmetry between dominant and non-dominant legs during unipodal jumps was shown to be a high risk factor of injury (Wang \& Fu, 2019). A video analysis of anterior cruciate ligament injuries during a reception in women's handball showed that body weight was unevenly distributed during the reception, and that impact velocity asymmetry is a major risk for anterior cruciate ligament injury (Olsen, Myklebust, Engebretsen, $\&$ Bahr, 2004). In the present population, $65 \%$ reported difficulties in performing the movement by their non-dominant side, which can explain the frequent use of their preferred side during practice.

Among extrinsic factors of injury, sport equipment is often put forward. Traceurs' equipment is rather simple, the only feature that could really make the difference is the footwear. Three main types of shoes have been identified among the parkour population. First, common running shoes with a positive drop from heel to forefoot and an important shock-absorbing heel arrive in first place, worn by $53 \%$ of the panel interviewed. Absorbing ground impacts with such traditional running sneakers, can be useful to reduce the incidence of lower limb injuries (Hayes \& Caplan, 2012). However, such running shoes, which design is based on comfort, cushioning, grip and stability of the foot are associated with a ground attack of the foot with the heel (Fredericks et al., 2015). This heel attack, allowed in particular by a thick sole, is however known to impose important constraints to the lower limb's joints, and to modify the natural sequence of muscle activation, proprioception and balance (Hardin, Van Den Bogert, \& Hamill, 2004; Squadrone, Rodano, Hamill, \& Preatoni, 2015). On the opposite, $12 \%$ of the participants reported to wear minimalist shoes. By having only a thin sole, this type of footwear can provide a much more important solicitation of the musculo-tendinous system of the lower limbs for shock absorbing. However, great risk of injury can occur during the transition from standard to minimalist if not performed progressively and appropriately (Goss \& Gross, 2012; Ryan, Elashi, Newsham-West, \& Taunton, 2014). In the present study, participants who wear minimalist shoes exhibited higher number of knee injuries. Therefore one should be careful in parkour using minimalist shoes, since 1) the landing surfaces in parkour are mostly very hard (concrete), 2) parkour can often lead to perform high drop jumps on such hard surfaces and 3) using those footwear require a familiarization especially if it follows years of wearing traditional running sneakers. Therefore, the safest use of minimalist shoes mainly depends upon the way of practicing parkour, avoiding high drop jumps and important impacts, unless the practitioner is a very well-trained athlete. Finally, an important proportion of participants (35\%) reported wearing a compromise between the common running sneaker and the minimalist shoes, i.e., footwear with a flat and light cushioning sole. This last solution could be a great deal to provide a more natural landing and jumping movement with a greater participation of foot and ankle muscles than usual sneakers, while still providing more cushioning than minimalist shoes.

Regarding the landscape of training, which is also one of the main extrinsic factor that could impact training, the vast majority of participants reported practicing outdoor. The variety of surfaces, materials, weather and temperature conditions can therefore increase the probability of external risk factors of injuries. Although some of them are inherently unpredictable, it should be highlighted that special attention must be paid to all these factors when practicing outdoor. On the contrary, when practicing indoor, all these factors are easily controllable. Since an important proportion of traceurs practice both outdoor and indoor (87.7\%), it is also important to highlight the drawback of using indoor facilities for training. First, the overuse of protective equipment can lead to overconfidence regarding complex skills or jump with important distances. Second, the lack of variability of surfaces and weather conditions in indoor facilities does not fully prepare the traceur to manage all conditions of outdoor training. That said, it is easier and safer to go from outdoor to indoor practice than the opposite.

If the landscape can influence the behavior, the people surrounding the practitioners, whether they are training partner or public audience, might particularly represent an important risk, particularly at certain ages. A previous study pointed out that young traceurs have a significantly higher score than other sport practitioners like gymnasts on the sensation-seeking scale, as well as on the personality inventory narcissist (Cazenave \& Michel, 2008). Narcissist individuals tend to have high levels of sensation-seeking (Emmons, 1987) in order to increase their self-esteem, therefore being less reluctant to take risks (Baumeister, Heatherton, \& Tice, 1993). Albeit indirectly, these points therefore constitute a risk factor for injury particularly for young practitioners. However, a few participants of the present study $(7.2 \%)$ confessed the feeling that they got injured due to an overestimation of their capacities after listening their training partner urging them to perform the jump. An important proportion of participants (more than $25 \%$ ) also felt they got injured because of the pressure they have imposed on themselves. This last assumption is even more important for autonomous practitioners. Over the 180 participants, more than $40 \%$ declared starting parkour without any coaching or advices from more experienced practitioners. A clear link between the presence of a coach and injury incidence is not always reported in sport (Egermann et al., 2003). In parkour, it not clear either that not being coached could be a risk factor for parkour injury (Greenberg \& Culver, 2020). Nonetheless, we still believe that the lack of supervision could represent a risk for injuries, especially because parkour practitioners are mostly young. Developing parkour organizations with 
professional and experienced coaches as well as increasing consciousness of the importance of coaching can therefore put the beginner practitioner in the right path to avoid important and dramatic errors. Therefore, one should no neglect the impact of stress induced by external motivations.

\subsection{Study limitations}

The assessment of causality between a priori identified risk of injury and data collected a posteriori by questionnaire can largely be questioned contrary, for instance, to a longitudinal follow-up of a tracer population. This is why the statistical analysis was limited in the present study, to avoid bias usually blamed in sport-injury literature. In sport-injury statistics, it was recommended to avoid establishing direct causality based on correlations analysis and avoid absolute measures of correlations (Nielsen et al., 2018). Although this may limit the interpretation of the present results, we mostly choose to stay descriptive to avoid over-interpretation of the data collected by questionnaires.

In such type of study, the composition of population tested has a very large importance. Although we tried to have a representative panel in terms of age, gender or training experience, it is possible that such result quickly evolves with time. The way and purposes to practice parkour can widely influence the risk of injuries, i.e., whether it is a leisure or a professional activity. Previous studies show that the injury rate among high-performance athletes in different sports (including gymnastics) is much more important in periods of competitions than in usual training (Marshall, Covassin, Dick, Nassar, \& Agel, 2007; Rechel, Yard, \& Comstock, 2008). In parkour, competitions are not yet very developed but some of the practitioners still become professionals, mostly for entertainment industry. Given the stress induced by a public representation and the frequency of these latter, these practitioners can easily be compared to professional athletes. A very few traceurs of the panel represented here were considered as such. It could be interesting to focus on these specific athletes who present very important training load and pressure from sponsors and public audience. Given the development of parkour competitions, the present study could be repeated in the future with competitive practitioners.

\subsection{Recommendations}

Although the training seemed well organized to provide sufficient rest and limit the training duration for most of the practitioners, some aspects can be pointed out. We strongly advice practitioners to warm-up, and more particularly to take attention to provide sufficient mechanical stress to their joints, common light joint mobility or stretching strategies being inefficient or even counter-productive to properly prepare the body to the high impact of parkour. However, it is recommended to practice stretching, not right at the end of the training session (which can, in fact, increase muscle damages) but rather at different times during the week. Our efforts should focus on improving awareness about dehydration and nutritional aspect, as a study has shown that the more nutritional knowledge athletes have, the greater the amount of water they ingest (Carvalho et al., 2011).

Simple landing techniques used by most of the participants seemed safe. However, when can recommend to increase the use of roll at landing technique to limit even more the impact. To reduce lower limb asymmetries, it could be recommended to train as much as possible in both side when performing unilateral techniques, or even to focus on the non-dominant limb to reduce the gap between limb strength and other biomechanical parameters.

Regarding the choice of footwear, it depends upon the type of practice (e.g., with high drop jumps or not). As the use of minimalist shoes has spread in the parkour community, if this material is used we recommend to be careful to ensure a transition time between traditional sneakers and such footwear. On the opposite, beginners should also be careful about high-cushioning shoes that could alter sensations and deteriorate the landing technique (i.e., generate a more "heel-landing" behavior).

We also strongly recommend not to start parkour alone and want to raise awareness that proper parkour coaching should be used and developed for anyone who wants to begin parkour. This is of important especially for young traceurs who, in addition to learn proper techniques, also necessitates education regarding risk-taking behaviors.

Finally, as many participants reported to continue practicing in presence of pain after an injury, we strongly recommended practitioners to respect more the resting times to allow a better recovery and limit the risk of recurrence.

\section{Conclusion}

Parkour is a young discipline with increasing audience through the spectacular performances often displayed online. Yet, the formal organization of this discipline, as the training habits of its practitioners, is still poorly documented. The present study brought further insights onto the training characteristics and injury risks of a representative population. Contrary to its apparent lack of framework regarding training organization, traceurs appeared to have established on their own a training routine including warm-ups, stretching, and physical conditioning. They also exhibited a low rate of injuries as compared to other discipline. The development of proper physical preparation and training methods specifics to parkour in the future will help decrease even more the risk of injuries.

Acknowledgements. The authors would like to thank the participants for their time and enthusiasm. The authors are particularly grateful to the French Parkour Federation (Federation de Parkour, FPK) for its help and support. 


\section{Conflict of interest}

The authors declared no potential conflicts of interest with respect to the research, authorship, and/or publication of this article.

\section{Certification of Non-Publication}

I, the undersigned, Sidney Grosprêtre, corresponding author, certify that the material in the article entitled "Training habits and lower limb injury prevention in parkour practitioners" has not been published and is not otherwise submitted for publication.

\section{References}

Baumeister, R.F., Heatherton, T.F., \& Tice, D.M. (1993). When ego threats lead to self-regulation failure: Negative consequences of high self-esteem. Journal of Personality and Social Psychology, 64(1), 141-156. https://doi.org/10.1037//00223514.64.1.141

Behm, D.G., \& Kibele, A. (2007). Effects of differing intensities of static stretching on jump performance. European Journal of Applied Physiology, 101(5), 587-594. https://doi.org/ 10.1007/s00421-007-0533-5.

Bressel, E., \& Cronin, J. (2005). The landing phase of a jump strategies to minimize injuries. Journal of Physical Education, Recreation \& Dance, 76(2), 30-35. https://doi.org/ 10.1080/07303084.2005.10607332.

Brown, T.N., O’Donovan, M., Hasselquist, L., Corner, B., \& Schiffman, J.M. (2016). Lower limb flexion posture relates to energy absorption during drop landings with soldier-relevant body borne loads. Applied Ergonomics, 52, 54-61. https:// doi.org/10.1016/j.apergo.2015.06.004.

Carvalho, P., Oliveira, B., Barros, R., Padrão, P., Moreira, P., \& Teixeira, V.H. (2011). Impact of fluid restriction and ad libitum water intake or an $8 \%$ carbohydrate-electrolyte beverage on skill performance of elite adolescent basketball players. International Journal of Sport Nutrition and Exercise Metabolism, 21(3), 214-221. https://doi.org/ 10.1123/ijsnem.21.3.214.

Cazenave, N., \& Michel, G. (2008). Conduites à risques et variation de l'estime de soi chez les adolescents : l'exemple du parkour. Annales Médico-Psychologiques, Revue Psychiatrique, 166(10), 875-881. https://doi.org/10.1016/j. amp.2008.10.026.

Collins, K., Wagner, M., Peterson, K., \& Storey, M. (1989). Overuse injuries in triathletes: A study of the 1986 Seafair Triathlon. The American Journal of Sports Medicine, 17(5), 675-680. https://doi.org/10.1177/036354658901700515.

Cortes, N., Onate, J., Abrantes, J., Gagen, L., Dowling, E., \& Van Lunen, B. (2007). Effects of gender and foot-landing techniques on lower extremity kinematics during drop-jump landings. Journal of Applied Biomechanics, 23(4), 289-299. https://doi.org/10.1123/jab.23.4.289.

Da Rocha, J.A., Pérez Morales, J.C., Schayer Sabino, G., Abreu, B.J., Carvalho Felicio, D., Drummond, M.D.M., \& Szmuchrowski, L.A. (2014). Prevalence and risk factors of musculoskeletal injuries in parkour. Archives of Budo Science of Martial Arts and Extreme Sports, 10(0). http://smaes. archbudo.com/view/abstracts/issue_id/10744.
Egermann, M., Brocai, D., Lill, C.A., \& Schmitt, H. (2003). Analysis of injuries in long-distance triathletes. International Journal of Sports Medicine, 24(4), 271-276. https://doi.org/ $10.1055 / \mathrm{s}-2003-39498$.

Emmons, R.A. (1987). Narcissism: Theory and measurement. Journal of Personality and Social Psychology, 52(1), 11-17. https://doi.org/10.1037//0022-3514.52.1.11

Fredericks, W.H., Swank, S., Teisberg, M., Hampton, B., Ridpath, L.C., \& Hanna, J. (2015). Lower extremity biomechanical relationships with different speeds in traditional, minimalist, and barefoot footwear. J Sports Sci Med, $14(2), 276-283$.

Giordano, B., \& Weisenthal, B. (2014). Prevalence and incidence rates are not the same: Response. Orthopaedic Journal of Sports Medicine, 2(7). SAGE Publications Ltd. https://doi. org $/ 10.1177 / 2325967114543261$.

Goss, D., \& Gross, M. (2012). Relationships among self-reported shoe type, footstrike pattern, and injury incidence. US Army Med Dep J, 25-30.

Greenberg, E., \& Culver, D.M. (2020). How parkour coaches learn to coach: Coaches' sources of learning in an unregulated sport. Journal of Adventure Education and Outdoor Learning, 20(1), 15-29. https://doi.org/10.1080/ 14729679.2018.1557060.

Greenleaf, J.E., Bernauer, E.M., Juhos, L.T., Young, H.L., Morse, J.T., \& Staley, R.W. (1977). Effects of exercise on fluid exchange and body composition in man during 14 day bed rest. Journal of Applied Physiology Respiratory Environmental and Exercise Physiology, 43(1), 126-132. https://doi.org/ 10.1152/jappl.1977.43.1.126.

Grosprêtre, S., \& Lepers, R. (2016). Performance characteristics of parkour practitioners: Who are the traceurs? European Journal of Sport Science, 16(5), 526-535. https://doi.org/ 10.1080/17461391.2015.1060263.

Gross, T.S., \& Nelson, R.C. (1988). The shock attenuation role of the ankle during landing from a vertical jump. Medicine and Science in Sports and Exercise, 20(5), 506-514. https://doi. org/10.1249/00005768-198810000-00013.

Hardin, E.C., Van Den Bogert, A.J., \& Hamill, J. (2004). Kinematic adaptations during running: Effects of footwear, surface, and duration. Medicine and Science in Sports and Exercise, 36(5), 838-844. https://doi.org/10.1249/01. MSS.0000126605.65966.40.

Hayes, P., \& Caplan, N. (2012). Foot strike patterns and ground contact times during high-calibre middle-distance races. Journal of Sports Sciences, 30(12), 1275-1283. https://doi. org/10.1080/02640414.2012.707326.

Hess, G.W. (2010). Achilles tendon rupture: A review of etiology, population, anatomy, risk factors, and injury prevention. Foot \& Ankle Specialist, 3(1), 29-32. https://doi.org/ $10.1177 / 1938640009355191$.

Hillyer, M., Menon, K., \& Singh, R. (2015). The effects of dehydration on skill-based performance. International Journal of Sports Science, 5(3), 99-107. http://article.sapub.org/ 10.5923.j.sports.20150503.02.html.

Hume, P.A., \& Steele, J.R. (2000). A preliminary investigation of injury prevention strategies in netball: Are players heeding the advice? Journal of Science and Medicine in Sport, 3(4), 406-413. https://doi.org/10.1016/S1440-2440(00)80007-9.

Jamtvedt, G., Herbert, R.D., Flottorp, S., Odgaard-Jensen, J., Håvelsrud, K., Barratt, A., Mathieu, E., Burls, A., \& Oxman, A.D. (2010). A pragmatic randomised trial of stretching before and after physical activity to prevent injury and soreness. British Journal of Sports Medicine, 44(14), 10021009. https://doi.org/10.1136/bjsm.2009.062232. 
Kay, A.D., \& Blazevich, A.J. (2012). Effect of acute static stretch on maximal muscle performance: A systematic review. Medicine and Science in Sports and Exercise, 44(1), 154164. https://doi.org/10.1249/MSS.0b013e318225cb27.

Leppilahti, J., \& Orava, S. (1998). Total achilles tendon rupture. A review. Sports Medicine, 25(2), 79-100. https://doi.org/ 10.2165/00007256-199825020-00002.

Longo, U.G., Petrillo, S., Maffulli, N., \& Denaro, V. (2013). Acute achilles tendon rupture in athletes. Foot and Ankle Clinics, 18(2), 319-338. https://doi.org/10.1016/j. fcl.2013.02.009.

Lund, H., Vestergaard-Poulsen, P., Kanstrup, I.L., \& Sejrsen, P. (1998). The effect of passive stretching on delayed onset muscle soreness, and other detrimental effects following eccentric exercise. Scandinavian Journal of Medicine and Science in Sports, 8(4), 216-221. https://doi.org/10.1111/ j.1600-0838.1998.tb00195.x.

Maldonado, G., Soueres, P., \& Watier, B. (2018). Strategies of parkour practitioners for executing soft precision landings. Journal of Sports Sciences, 36(22), 2551-2557.

Marshall, S.W., Covassin, T., Dick, R., Nassar, L.G., \& Agel, J. (2007). Descriptive epidemiology of collegiate women's gymnastics injuries: National Collegiate Athletic Association injury surveillance system, 1988-1989 through 2003-2004. Journal of Athletic Training, 42(2), 234-240. Association, Inc. www.journalofathletictraining.org.

Mazzone, M.F., \& Mccue, T. (2002). Common conditions of the Achilles tendon. American Family Physician, 65(9), 18051810 .

Minogue, E. (2018). Parkour Earth issues an Open Letter to member National Gymnastics Federations of the FIG. https://parkour.earth/parkour-earth-issues-an-open-letterto-member-national-gymnastics-federations-of-the-fig.

Nielsen, R.O., Chapman, C.M., Louis, W.R., Stovitz, S.D., Mansournia, M.A., Windt, J., Møller, M., Parner, E.T., Hulme, A., Bertelsen, M.L., Finch, C.F., Casals, M., \& Verhagen, E. (2018). Seven sins when interpreting statistics in sports injury science. British Journal of Sports Medicine, 52(22), 1410-1412. https://doi.org/10.1136/bjsports-2017098524 .

O'toole, M.L., Hiller, W.D.B., Smith, R.A., \& Sisk, T.D. (1989). Overuse injuries in ultraendurance triathletes. The American Journal of Sports Medicine, 17(4), 514-518. https://doi.org/ $10.1177 / 036354658901700411$.

Olsen, O.E., Myklebust, G., Engebretsen, L., \& Bahr, R. (2004). Injury mechanisms for anterior cruciate ligament injuries in team handball: A systematic video analysis. American Journal of Sports Medicine, 32(4), 1002-1012. https://doi. org $/ 10.1177 / 0363546503261724$.

Park, D.Y., Rubenson, J., Carr, A., Mattson, J., Besier, T., \& Chou, L.B. (2011). Influence of stretching and warm-up on Achilles tendon material properties. Foot and Ankle International, 32(4), 407-413. https://doi.org/10.3113/FAI.2011.0407.

Parkkari, J., Kannus, P., Natri, A., Lapinleimu, I., Palvanen, M., Heiskanen, M., Vuori, I., \& Järvinen, M. (2004). Active living and injury risk. International Journal of Sports Medicine, 25 (3), 209-216. https://doi.org/10.1055/s-2004-819935.

Pieters, D., Wezenbeek, E., De Ridder, R., Witvrouw, E., \& Willems, T. (2020). Acute effects of warming up on achilles tendon blood flow and stiffness-PubMed. J Strength Cond Res. https://doi.org/10.1519/JSC.0000000000003931.

Puddle, D.L., \& Maulder, P.S. (2013). Ground reaction forces and loading rates associated with parkour and traditional drop landing techniques. Journal of Sports Science $\mathcal{G}$
Medicine, 12(1), 122-129. http://www.pubmedcentral.nih. gov $/$ articlerender.fcgi?artid $=3761764 \&$ tool $=$ pmcentrez\& rendertype $=$ abstract.

Rechel, J.A., Yard, E.E., \& Comstock, R.D. (2008). An epidemiologic comparison of high school sports injuries sustained in practice and competition. Journal of Athletic Training, 43(2), 197-204. https://doi.org/10.4085/10626050-43.2.197.

Rossheim, M.E., \& Stephenson, C.J. (2017). Parkour injuries presenting to United States emergency departments, 20092015. American Journal of Emergency Medicine, 35(10), 1503-1505. https://doi.org/10.1016/j.ajem.2017.04.040.

Ryan, M., Elashi, M., Newsham-West, R., \& Taunton, J. (2014). Examining injury risk and pain perception in runners using minimalist footwear. British Journal of Sports Medicine, 48 (16), 1257-1262. https://doi.org/10.1136/bjsports-2012092061.

Safran, M.R., Garrett, W.E., Seaber, A.V., Glisson, R.R., \& Ribbeck, B.M. (1988). The role of warmup in muscular injury prevention. The American Journal of Sports Medicine, 16(2), 123-129. https://doi.org/10.1177/036354658801600206.

Shrier, I. (2004). Does stretching improve performance? A systematic and critical review of the literature. Clinical Journal of Sport Medicine, 14(5), 267-273. https://doi.org/ 10.1097/00042752-200409000-00004.

Squadrone, R., Rodano, R., Hamill, J., \& Preatoni, E. (2015). Acute effect of different minimalist shoes on foot strike pattern and kinematics in rearfoot strikers during running. Journal of Sports Sciences, 33(11), 1196-1204. https://doi. org $/ 10.1080 / 02640414.2014 .989534$.

Standing, R.J., \& Maulder, P.S. (2015). A comparison of the habitual landing strategies from differing drop heights of parkour practitioners (traceurs) and recreationally trained individuals. Journal of Sports Science \& Medicine, 14(4), 723-731. http://www.ncbi.nlm.nih.gov/pubmed/26664268.

Strafford, B.W., van der Steen, P., Davids, K., \& Stone, J.A. (2018). Parkour as a donor sport for athletic development in youth team sports: Insights through an ecological dynamics lens. Sports Medicine-Open, 4(1), 21. https://doi.org/ 10.1186/s40798-018-0132-5.

Summitt, R.J., Cotton, R.A., Kays, A.C., \& Slaven, E.J. (2016). Shoulder injuries in individuals who participate in crossfit training. Sports Health, 8(6), 541-546. https://doi.org/ $10.1177 / 1941738116666073$.

Van Gent, R.N., Siem, D., Van Middelkoop, M., Van Os, A.G., Bierma-Zeinstra, S.M.A., \& Koes, B.W. (2007). Incidence and determinants of lower extremity running injuries in long distance runners: A systematic review. British Journal of Sports Medicine, 41(8), 469-480. https://doi.org/10.1136/ bjsm.2006.033548.

Vleck, V.E., \& Garbutt, G. (1998). Injury and training characteristics of male elite, development squad, and club triathletes. International Journal of Sports Medicine, 19(1), 38-42. https://doi.org/10.1055/s-2007-971877.

Wang, J., \& Fu, W. (2019). Asymmetry between the dominant and non-dominant legs in the lower limb biomechanics during single-leg landings in females. Advances in Mechanical Engineering, 11(5), 168781401984979. https://doi.org/ $10.1177 / 1687814019849794$.

Winchester, J.B., Nelson, A.G., Landin, D., Young, M.A., \& Schexnayder, I.C. (2008). Static stretching impairs sprint performance in collegiate track and field athletes. Journal of Strength and Conditioning Research, 22(1), 13-18. https:// doi.org/10.1519/jsc.0b013e31815ef202. 
Zhang, S.N., Bates, B.T., \& Dufek, J.S. (2000). Contributions of lower extremity joints to energy dissipation during landings. Medicine and Science in Sports and Exercise, 32(4), 812-819. https://doi.org/10.1097/ 00005768-200004000-00014.
Zwingenberger, S., Valladares, R.D., Walther, A., Beck, H., Stiehler, M., Kirschner, S., Engelhardt, M., \& Kasten, P. (2014). An epidemiological investigation of training and injury patterns in triathletes. Journal of Sports Sciences, 32(6), 583590. https://doi.org/10.1080/02640414.2013.843018.

Cite this article as: Grosprêtre S \& El Khattabi S (2022) Training habits and lower limb injury prevention in parkour practitioners. Mov Sport Sci/Sci Mot, 115, 43-55 